\title{
Experimental and Modeling Study of Galactosyl-Oligosaccharides Forma- tion in Continuous Recycle Membrane Reactors (CRMR)
}

\author{
Roberto Gonzalez ${ }^{1}$, Mehrdad Ebrahimi ${ }^{2}$ and Peter Czermak*,2,3 \\ ${ }^{I}$ Polytechnic University of Nicaragua (UPOLI), Biotechnology Center (CEBiot), Costado Sur Villa Rubén Darío, \\ Managua, Nicaragua \\ ${ }^{2}$ University of Applied Sciences Giessen-Friedberg, Institute of Biopharmaceutical Technology (IBPT), Wiesenstrasse \\ 14, D-35390 Giessen, Germany \\ ${ }^{3}$ Kansas State University, Department of Chemical Engineering, 105 Durland Hall, Manhattan, KS 66506, USA
}

\begin{abstract}
Galactosyl-oligosaccharides (GOS) can be produced with native enzymes in Continuous Recycle Membrane Reactors (CRMR) or with immobilized enzymes in Plug Flow Bed Reactors (PFBR). In this paper a simple three kinetic constants model was implemented and used to define the optimal operation conditions to obtain a higher GOS yield. Experimental GOS yield and productivity obtained with CRMR were in good agreement with simulated results. The advantages of using single CRMR, two coupled CRMR and single CRMR coupled with Simulated Moving Bed Chromatography (SMBC), for product separation and continuous lactose recycling, were investigated with a modeling and experimental study. Experimental studies for single CRMR showed a $89 \%$ higher amount of produced GOS than reports from immobilized enzymes in Plug Flow Bed Reactors (PFBR). Two coupled CRMR produced a $25 \%$ higher amount of GOS than single CRMR. Simulated results with CRMR and SMBC for continuous lactose recycling showed $45 \%$ higher GOS amount than single CRMR. The results prove the feasibility and advantages of GOS production in single or series CRMR with native enzymes with or without lactose recycling.
\end{abstract}

Keywords: Oligosaccharides, lactose, enzymatic catalysis, continuous recycle membrane reactor, ultra filtration, plug flow bed reactor.

\section{INTRODUCTION}

Enzymatic hydrolysis of lactose is accompanied by galactosyl transfer to other sugars, thereby producing oligosaccharides (Fig. 1). These are hydrolyzed slowly, both in vitro and in vivo. They can be thought of as low molecular weight, non-viscous, water-soluble, dietary fibre. They are considered to be physiologically functional foods which promote the growth of bifidobacteria in the colon and a wide variety of health benefits has been claimed in connection with this effect [1-3].

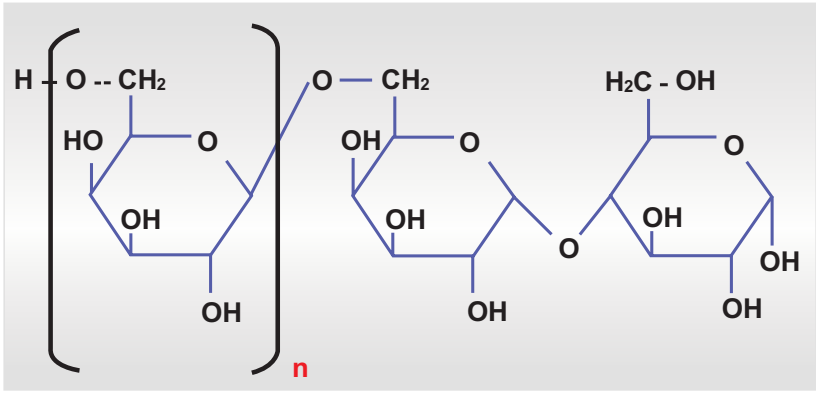

Fig. (1). General chemical structure of galactosyl-oligosaccharides [1].

\footnotetext{
*Address correspondence to this author at the University of Applied Sciences Giessen-Friedberg, Institute of Biopharmaceutical Technology-IBPT, Wiesenstrasse 14, D-35390 Giessen, Germany;

E-mail: peter.czermak@tg.fh-giessen.de
}

A serious issue in this enzymatic catalysis is the enzymatic hydrolysis of the newly formed oligosaccharides back to lactose and the monomers. A number of steps could be taken to avoid this, namely use of highly concentrated substrate, lowering of the thermodynamic activity of water, modification of the enzyme, and rapid removal of the valuable product from the reaction mixture [4].

The amount and nature of the oligosaccharides formed depends upon several factors including the enzyme source, the concentration and nature of the substrate, the degree of conversion of the substrate and the reaction conditions. Their rigorous modeling leads to complex kinetic equations with a large number of constants. Such models are unwieldy and are usually not suitable for practical purpose [5].

A more simplified approach was developed in this paper and a practical mathematical model was obtained, useful to define the optimal combination of operation conditions in order to obtain higher Galactosyl-oligosaccharides (GOS) yield.

GOS can be produced with native enzymes in Continuous Recycle Membrane Reactors (CRMR) or with immobilized enzymes in Plug Flow Bed Reactors (PFBR) [1, 6-9]. With immobilized enzymes a significant portion of the oligosaccharides appears to be enzymatic hydrolyzed before reaching the bulk solution from where the valuable product could be recovered $[6,10]$. However, GOS production from immobilized enzymes in PFBR had not been addressed very well up to now [6-9]. Some limitations for PFBR have been associated to the carrier used for enzyme immobilization. 
With variation of initial lactose concentration and residence time in CRMR and PFBR, an optimum in product concentration is obtained [6] and it is necessary to develop another way in order to increase GOS production beyond this limit. One possibility could be the recycling of lactose and producing GOS, glucose and galactose, using Simulated Moving Bed Chromatography (SMBC) in order to obtain complete conversion of lactose in GOS.

In this study the suitability of a system of two CRMR in series, which combine the advantages of traditional CSTR and PFR characteristics, was investigated in a modeling and experimental study and a system with a single CRMR with lactose recirculation was investigated in a modeling study.

\section{MATERIALS AND METHODS}

\subsection{One and Two Stage System Experiments}

One stage experiments were realized in a 2 liter maximum volume CRMR with a membrane module as shown in Fig. (2). The enzyme is retained in the reactor while a solution containing the relatively low molecular weight products (oligosaccharides), some of the substrate (lactose) and some by-products (glucose, galactose) pass through the membrane.

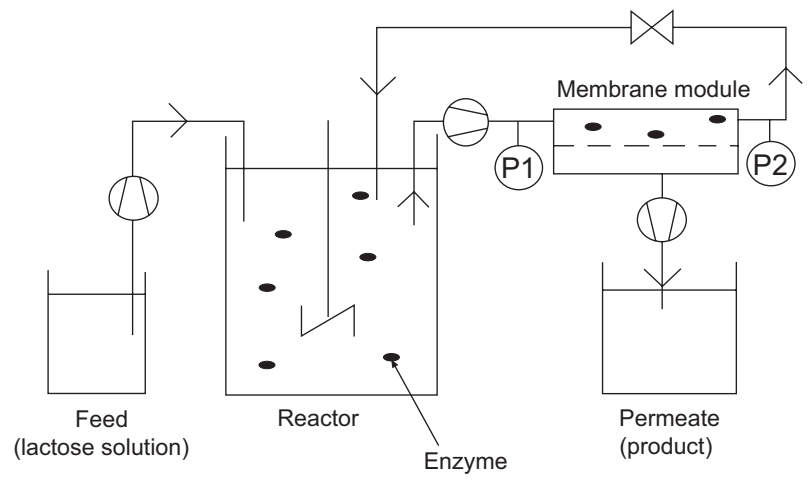

Fig. (2). Laboratory scale single stage CRMR system (membraneassisted reactor system).

Based on the large difference between the nominal molecular weight cut-off of the membranes and the molecular weight of the materials involved, it is reasonable to assume that retentate composition is identical to the permeate composition, except for the presence of enzyme in retentate. No leakage of enzymes was observed as determined by measurement of the enzyme activity in permeate.
The CRMR apparatus used in this study and the applied operational settings have been described in details in a previous work [1]. In brief, the pressure readings of P1 and P2 (Fig. 2) were always approximately equal. This pressure is reported as the trans-membrane pressure (TMP). No permeate was recycled. Different average residence times (0.5 and 1 hour) were achieved by keeping the permeate flux (20 $\mathrm{l} \mathrm{m}^{-2} \mathrm{hr}^{-1}$ ) and feed flow rate constant and equal while using different reactor volumes. Enzyme was surplus always in excess. For two stages experiments, a couple of 2 liter maximum volume CRMR was utilized, as shown in Fig. (3).

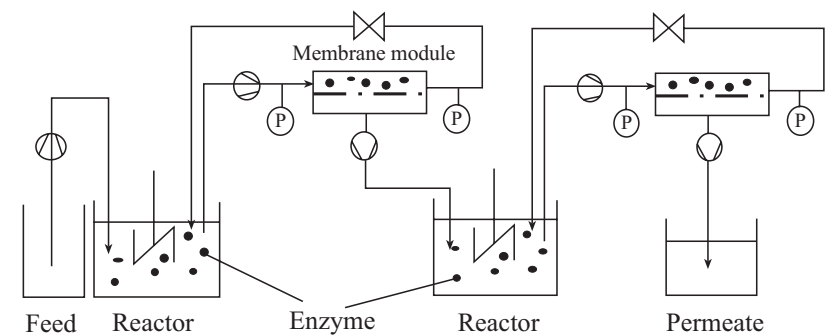

Fig. (3). Laboratory scale two CRMR in series system (membraneassisted reactor system).

\subsection{Enzymes}

Sources, properties, and experimental conditions for the commercial $\beta$-galactosidases used in this work are given in Table 1. $\beta$-galactosidase from Maxilact has a molecular weight exceeding $135,000 \mathrm{~g} / \mathrm{mol}$ [11]. This is clearly above the nominal molecular weight cut-off (MWCO) of the membrane used here $(20,000 \mathrm{~g} / \mathrm{mol})$.

\subsection{Membranes}

The ceramic membrane used here (Atech Innovations GmbH, Gladbeck, Germany) was a cylindrical monolith (diameter $25.4 \mathrm{~mm}$ ) with 19 flow channels for the feed (selective layer $\mathrm{TiO}_{2}$ on $\mathrm{ZrO}_{2}$, porous $\mathrm{Al}_{2} \mathrm{O}_{3}$ structural support (Fig. 4), flow channel diameter $3 \mathrm{~mm}$, total active filtration area of the monolith $0.1 \mathrm{~m}^{2}$ ). The monolith was contained in a stainless steel housing (Fig. 5). The nominal weight cut-off of the ceramic membrane is indicated by the manufacturer as $20.000 \mathrm{~g} / \mathrm{mol}$.

The membranes were rinsed after every experiment with copious amounts of the aqueous buffer solution containing 1 $\% \mathrm{NaOH}$.

Table 1. Sources and Properties of Enzymes

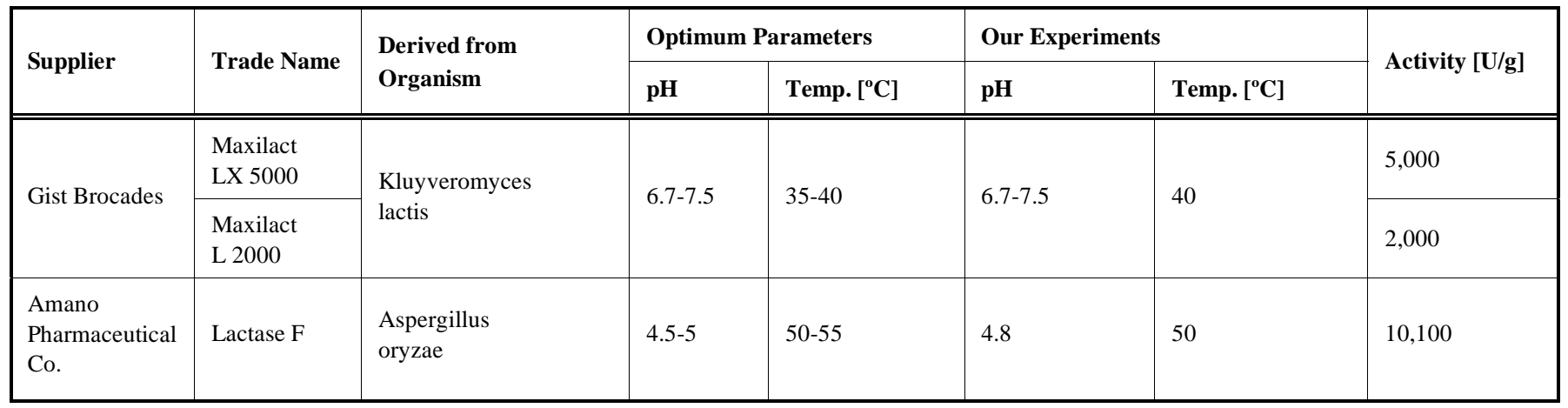




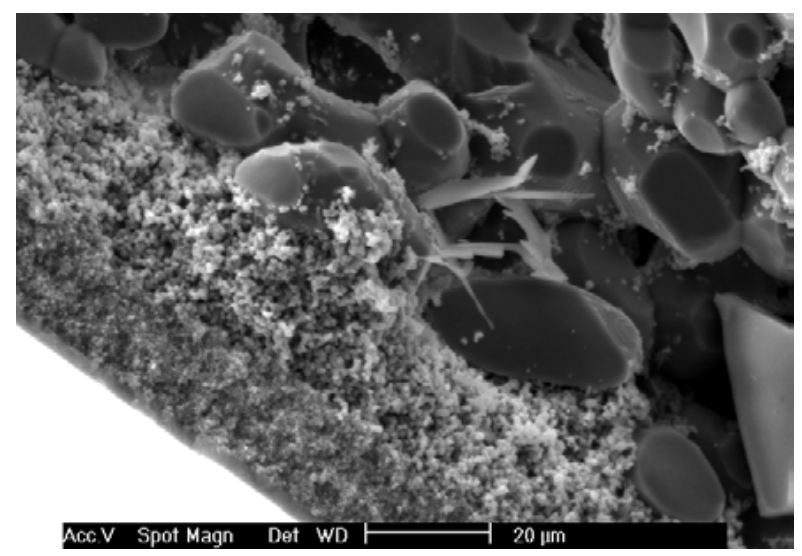

Fig. (4). SEM-micrograph of a ceramic ultrafiltration membrane.

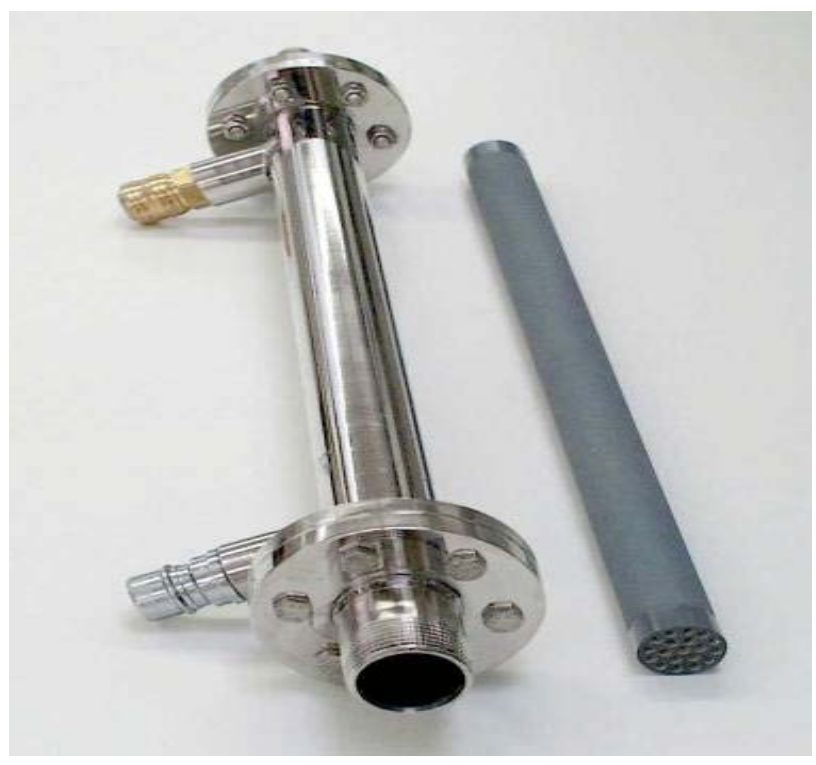

Fig. (5). Tubular membrane and module.

\subsection{Chemicals}

Deionized water was used. Potassium phosphate (5 mmol/l) was used as a buffer in all experiments. The $\alpha$ lactose was food grade $(99.95 \%$ pure, Meggle $\mathrm{GmbH}$, Wasserburg, Germany).

\subsection{Analytical}

High Performance Thin Layer Chromatography (HPTLC) using a Camag system (Linomat 5, TLC Scanner 3, Camag GmbH, Germany) was used to analyze the composition of products. Additionally, we used High Performance Anion Exchange Chromatography, Pulsed Amperometric Detection (HPAEC-PAD) using a Dionex system (Dionex Corporation, Sunnyvale, CA) and enzymatic assays as control.

\subsection{Software Tools}

For model design and construction the software Stella ${ }^{\circledR}$ 7.03 (HPS Inc., USA) [12] was used. The developed Stella ${ }^{\circledR}$ model was formed by several sectors. The differential and algebraic equations corresponding to all the sectors were uploaded into Berkeley Madonna ${ }^{\circledR} 8.01$ [13] in order to analyze the differential equations set.

\section{RESULTS}

\subsection{Model Development}

Galactosyl-oligosaccharides (GOS) can be derived from lactose by enzymatic catalysis using $\beta$-galactosidases. The amount and nature of the oligosaccharides formed in the enzymatic catalyzed process depends upon several factors including the enzyme source, the concentration and nature of the substrate, the degree of conversion of the substrate and the reaction conditions. The enzymatic lactose hydrolysis is a complex process involving a multitude of sequential reactions leading to higher saccharides (oligosaccharides) intermediates. A minimum of three steps were involved, the last of which allows for hydrolysis or transferase activity [4, 14]. It has been shown that trisaccharides dominated among various types of oligosaccharides $[4,15,16]$ and the model can be simplified by considering only the production of trisaccharides [17]. But the mechanistic model is rather complex even when only trisaccharides are considered:

$$
\begin{aligned}
& \mathrm{La}+\mathrm{E} \leftrightarrow \mathrm{LaE} \rightarrow \mathrm{Ga}+\mathrm{Gl}+\mathrm{E} \\
& \mathrm{GaE}+\mathrm{La} \leftrightarrow \mathrm{E}+\mathrm{Tr} \\
& \mathrm{GaE}+\mathrm{H}_{2} \mathrm{O} \rightarrow \mathrm{E}+\mathrm{Tr}
\end{aligned}
$$

This mechanism was utilized by Zhou and co workers [15] in order to develop a Michaelis-Menten kinetic equation with four constants $\left(\mathrm{V}_{\mathrm{m}}, \mathrm{K}_{\mathrm{m}}, \mathrm{K}_{\mathrm{i}}\right.$ and $\left.\mathrm{K}_{\mathrm{t}}\right)$ with good results in modeling lactose hydrolysis by a $\beta$-galactosidase from Kluyveromyces lactis immobilized in cotton fabric. Also a more complicated model considering the formation of both di- and tri oligosaccharides was proposed in order to obtain a better representation of experimental data for a recombinant $K$. lactis $\beta$-galactosidase for both hydrolysis and transgalactosylation [18].

A better approach to simplify the reaction mechanism is to neglect formation of enzyme substrate complexes altogether and to deal only with overall reactions of the reactants to products. In this case a model requiring only three kinetic constants $\left(\mathrm{K}_{\mathrm{i}}, \mathrm{K}_{1}\right.$ and $\left.\mathrm{K}_{2}\right)$ [17] is obtained:

$$
\begin{aligned}
& \mathrm{La} \stackrel{K_{1}}{\rightarrow} \mathrm{Ga}+\mathrm{Gl} \\
& \mathrm{La}+\mathrm{Ga} \stackrel{K_{1}}{\rightarrow} \mathrm{Ol} \\
& \mathrm{Ol} \stackrel{K_{2}}{\rightarrow} \mathrm{La}+\mathrm{Ga}
\end{aligned}
$$

For describing GOS production from lactose in a single CRMR, common mathematical models were taken from literature [5] based on the simplified kinetic approach selected. A set of differential equations was obtained, where subscript $\mathrm{rc}$, $\mathrm{rt}$ and $\mathrm{p}$ denote reactor, retentate and permeate volumes, flows and concentrations. Also $\mathrm{F}_{\mathrm{p} 1}$ and $\mathrm{F}_{\mathrm{p} 2}$ denote permeate flow in and out permeate vessel, $\mathrm{La}_{\mathrm{ro}}$ denotes initial reactor content of lactose and feed denotes feed flow. Moreover, flow from reactor to membrane module $\left(\mathrm{F}_{\mathrm{rc}}\right)$ and Retentate Flow to reactor $\left(F_{r t}\right)$ are considered internal flows, not included in mathematical model balance equations. 
The set of equations was developed in a general way, considering possibilities of batch, fed batch and continuous operation modes.

$$
\begin{aligned}
& \frac{d V_{r c}}{d t}=F e e d-F_{p 1} \\
& \frac{d V_{p}}{d t}=F_{p 1}-F_{p 2} \\
& \frac{d G a_{r c}}{d t}=L a_{r c} * k_{i}+O l_{r c} * k_{2}- \\
& L a_{r c} * G a_{r c} * k_{1} \\
& \frac{d G a_{p}}{d t}=\frac{F_{p 1} * G a_{r c}}{V_{r c}}-\frac{F_{p 2}-G a_{p}}{V_{p}} \\
& \frac{d G a_{p}}{d t}=\frac{F_{p 1} * G a_{r c}}{V_{r c}}-\frac{F_{p 2} * G a_{p}}{V_{p}} \\
& \frac{d G l_{p}}{d t}=\frac{F_{p 1} * G l_{r c}}{V_{r c}}-\frac{F_{p 2} * G l_{p}}{V_{p}} \\
& \frac{d L a_{r c}}{d t}=O l_{r c} * k_{2}-L a_{r c} * k_{i}- \\
& L a_{r c} * G a_{r c} * k_{1}+\frac{F e e d * L a_{r c o}}{V_{r c}}- \\
& \frac{F_{p 1} * L a_{r c}}{V_{r c}} \\
& \frac{d L a_{p}}{d t}=\frac{F_{p 1} * L a_{r c}}{V_{r c}}-\frac{F_{p 2} * L a_{p}}{V_{p}} \\
& \frac{d o l_{p}}{d t}=\frac{F_{p 1} * O l_{r c}}{V_{r c}} * G a_{r c} * k_{1}-O l_{r c} * \\
& F_{p 1}
\end{aligned}
$$

For model simulation the differential equation set from above, coupled with a set of algebraic equations and constants to describe the CRMR process, was transferred and solved by Runge Kutta procedure in Stella ${ }^{\circledR} 7.0 .3$ from HPS Inc., [12]. After the complete logical building of the model was finished, the system of algebraic and differential equations was transferred to Berkeley Madonna ${ }^{\circledR}$ 8.0.1 software [13] in order to validate the model with the aid of experimental data and to optimize model parameters.

The curve fit option was selected to optimize kinetic parameters of the model. With the statistical evaluation tool the fittings were subjected to a careful statistical analysis. The curve fitting procedure was based on selected experimental data from laboratory scale CRMR system steady-state conditions using two types of enzymes: Maxilact from $K$. lactis and Lactase F from A. oryzae (Table 1). With kinetic coefficients obtained the concentrations predicted by the model at the end of the running period, were very close to experimental results (Fig. 6). Thus, the simplified mathematical model obtained can be used to define the optimal operations conditions in order to obtain higher GOS yield.

\subsection{Modeling Study}

Based on the mathematical model for oligosaccharide formation in a single CRMR, previously developed by authors [19], the mathematical models for two CRMR reactors in series were developed. Also a simplified mathematic model was developed for PFBR. The model approach selected for PFBR was based on the fact that concentration characteristics of a tubular reactor, without packed bed limitations, are well approximated by a series of tank reactors [5]. Moreover when using three reactors in series, approximately $90 \%$ of the yield of a PFBR could be achieved and by addition of a fourth, the yield was only increased to $93 \%$ [20].

If packed bed limitations and specifically enzyme immobilization could be considered, a more complicated PFBR model will be obtained. In this study the simplified PFBR model, without carrier limitations considerations, was utilized. Carrier effects of immobilized enzymes were analyzed comparing simulated results from simplified PFBR model, with experimental results reported in literature [10].

Considering temperature and $\mathrm{pH}$ affect the reaction rate, but did not result in any change in GOS formation [10], all the simulations were performed with the same temperature and $\mathrm{pH}$ depending on the used enzyme. Using Berkeley Madonna ${ }^{\circledR}$ tools [13], an optimization of different initial batch time for a single CRMR enzymatic GOS production process was performed, based on the same temperature, $\mathrm{pH}$ and $30 \%$ initial lactose concentration. The results obtained showed that an initial batch time between 10 and 30 minutes must be obtained the best results.

Single CRMR simulations were performed with optimum initial batch time, initial lactose concentration between 200 and $400 \mathrm{~g} / \mathrm{L}$ and residence time between 0.25 and 1 hour.
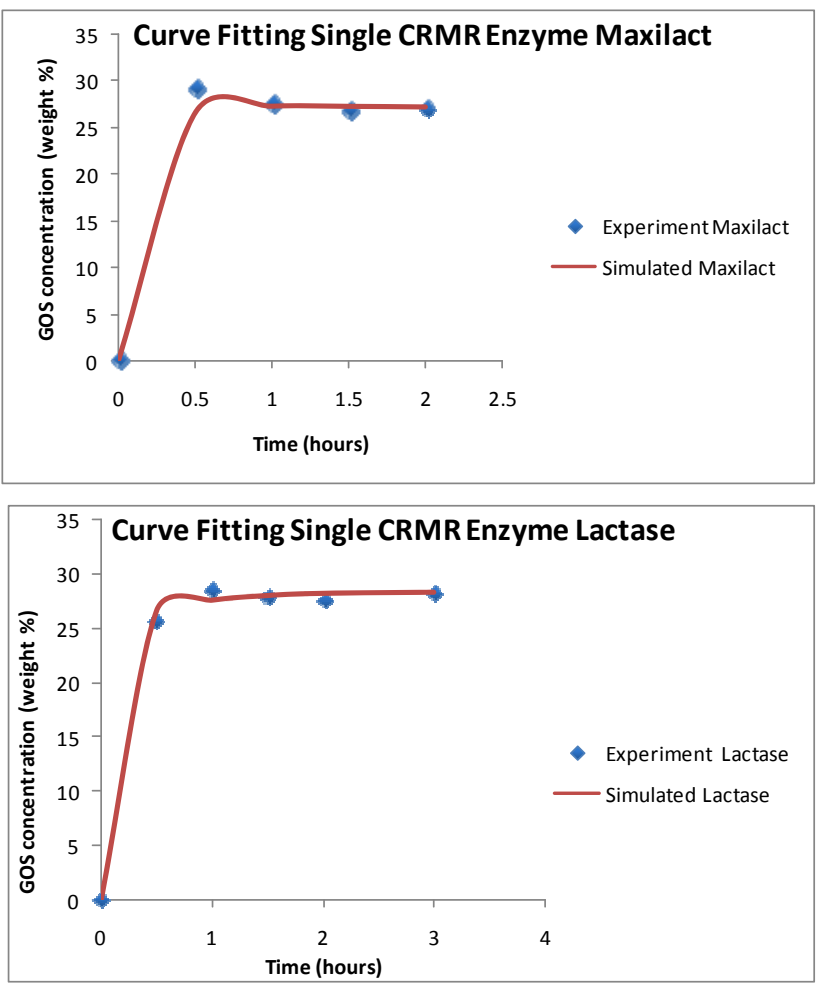

Fig. (6). Curve fitting single CRMR using enzymes Maxilact from $K$. lactis and Lactase F from A. oryzae, running with $200 \mathrm{~g} / \mathrm{L}$ initial lactose concentration and 0.5 hour residence time. 
Table 2. Single CRMR Final Simulated Results with Enzyme from K. lactis, Residence Time Between 0.25 and 1hour; Initial Lactose Concentration Between 200 and $400 \mathrm{~g} / \mathrm{L}$

\begin{tabular}{|l|l|l|l|}
\hline Residence Time $(\mathbf{h})$ & Initial Lactose Concentration $(\mathbf{g} / \mathbf{L})$ & GOS Fraction Weight $(\%)$ & Volumetric Productivity (g/L.h) \\
\hline \hline 0,25 & 200 & 22,5 & 172,6 \\
\hline 0,5 & 200 & 27,03 & 97,9 \\
\hline 1 & 200 & 27,2 & 44,3 \\
\hline 0,25 & 300 & 26,8 & 305 \\
\hline 0,5 & 300 & 31,8 & 170 \\
\hline 1 & 300 & 32 & 76 \\
\hline 0,25 & 400 & 30 & 450 \\
\hline 0,5 & 400 & 35 & 246 \\
\hline 1 & 400 & 35,4 & 110 \\
\hline
\end{tabular}

Table 3. Single CRMR Final Simulated Results with Enzyme from A. oryzae, Residence Time Between 0.25 and 1 hour; Initial Lactose Concentration Between 200 and $400 \mathrm{~g} / \mathrm{L}$

\begin{tabular}{|l|l|l|l|}
\hline Residence Time (h) & Initial Lactose Concentration (g/L) & GOS Fraction Weight ( \%) & Volumetric Productivity (g/L.h) \\
\hline \hline 0,25 & 200 & 24 & 181,3 \\
\hline 0,5 & 200 & 28,4 & 99,4 \\
\hline 1 & 200 & 28,4 & 43,3 \\
\hline 0,25 & 300 & 27,9 & 313,5 \\
\hline 0,5 & 300 & 32,7 & 168,5 \\
\hline 1 & 300 & 32,75 & 72,6 \\
\hline 0,25 & 400 & 30,5 & 454 \\
\hline 0,5 & 400 & 35,5 & 241 \\
\hline 1 & 400 & 35,6 & 103 \\
\hline
\end{tabular}

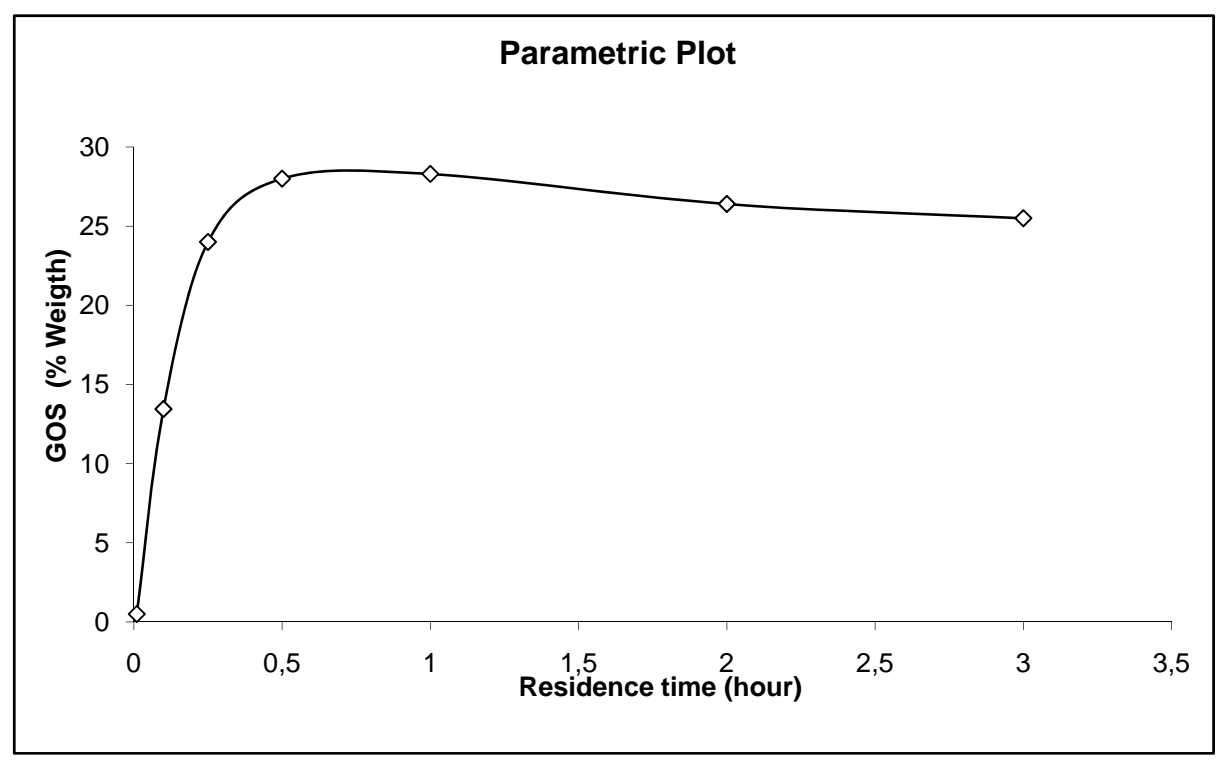

Fig. (7). Effect of residence time on GOS weight concentration in single CRMR with enzyme from A. oryzae and $200 \mathrm{~g} / \mathrm{L}$ initial lactose concentration. 


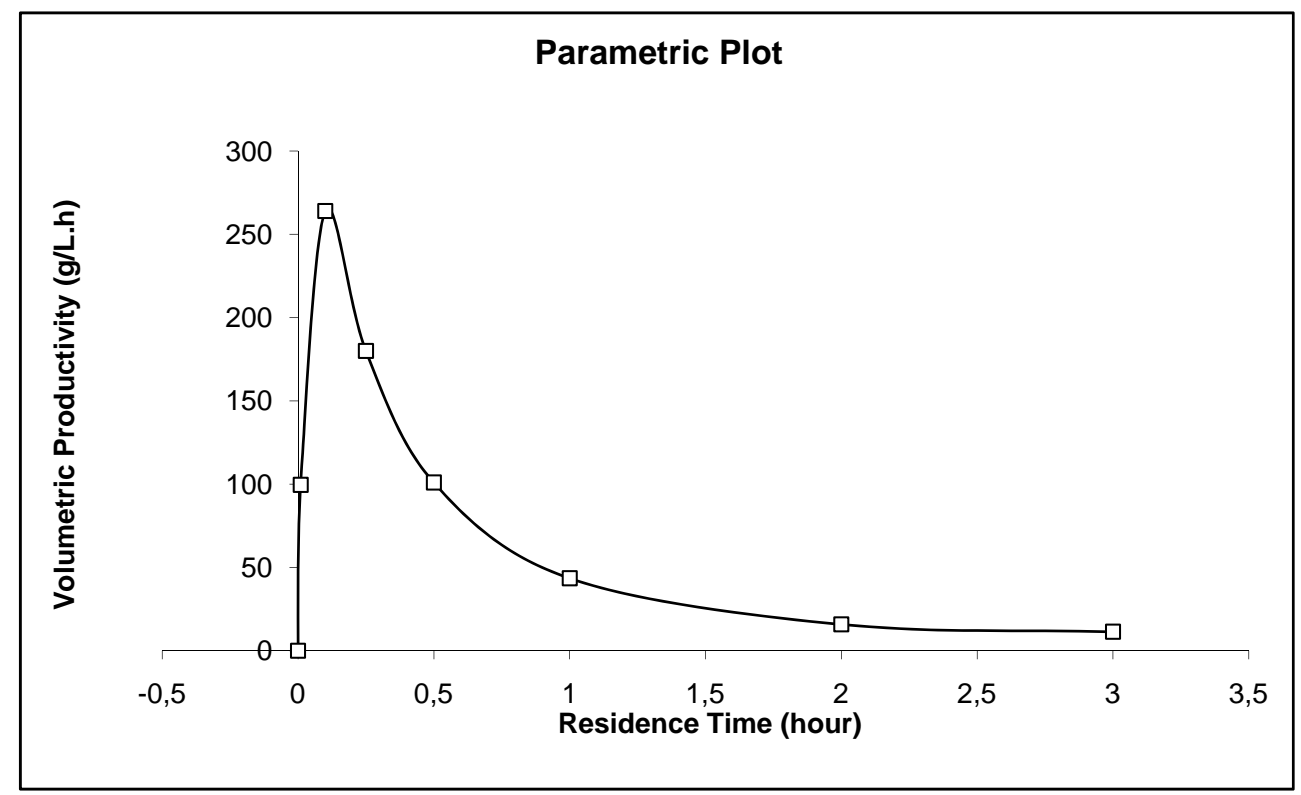

Fig. (8). Effect of residence time on GOS volumetric productivity in single CRMR with enzyme from A. oryzae and $200 \mathrm{~g} / \mathrm{L}$ initial lactose concentration.

Final simulated results (Tables 2,3 ) confirm, that initial lactose concentration is by far the most significant factor affecting GOS formation [3, 6]: the higher the initial lactose concentration is, the higher are GOS yield and volumetric productivity.

Residence time is another important factor, and a complete study of this factor was realized using Madonna $\mathrm{Pa}-$ rameter Plot option. Using enzyme from A. oryzae and $20 \%$ initial lactose concentration, GOS concentration at the end of every run was plotted versus residence time between 0.001 and 3 hours. Results obtained (Fig. 7) show an increase of GOS concentration in the beginning up to a maximum concentration obtained under 1 hour residence time. Later, GOS concentration decreases continuously with increased residence time.
But for economical production of GOS productivity is more important than GOS concentration [6]. A parametric plot of productivity versus residence time (Fig. 8) shows a productivity increase with increasing residence time between 0 to 0,1 hour. From this inflection point, the higher the residence time is, the lower is the productivity. Below 1 hour residence time, reduction of GOS concentration is compensated by much higher reactor productivity.

Consequently, better operation conditions could be obtained working with a higher initial lactose concentration (30\% weight or higher) and lower residence time $(0.5$ or lower), limited only by membrane flow possibility and global process economic considerations related with concentration of lactose in raw material.

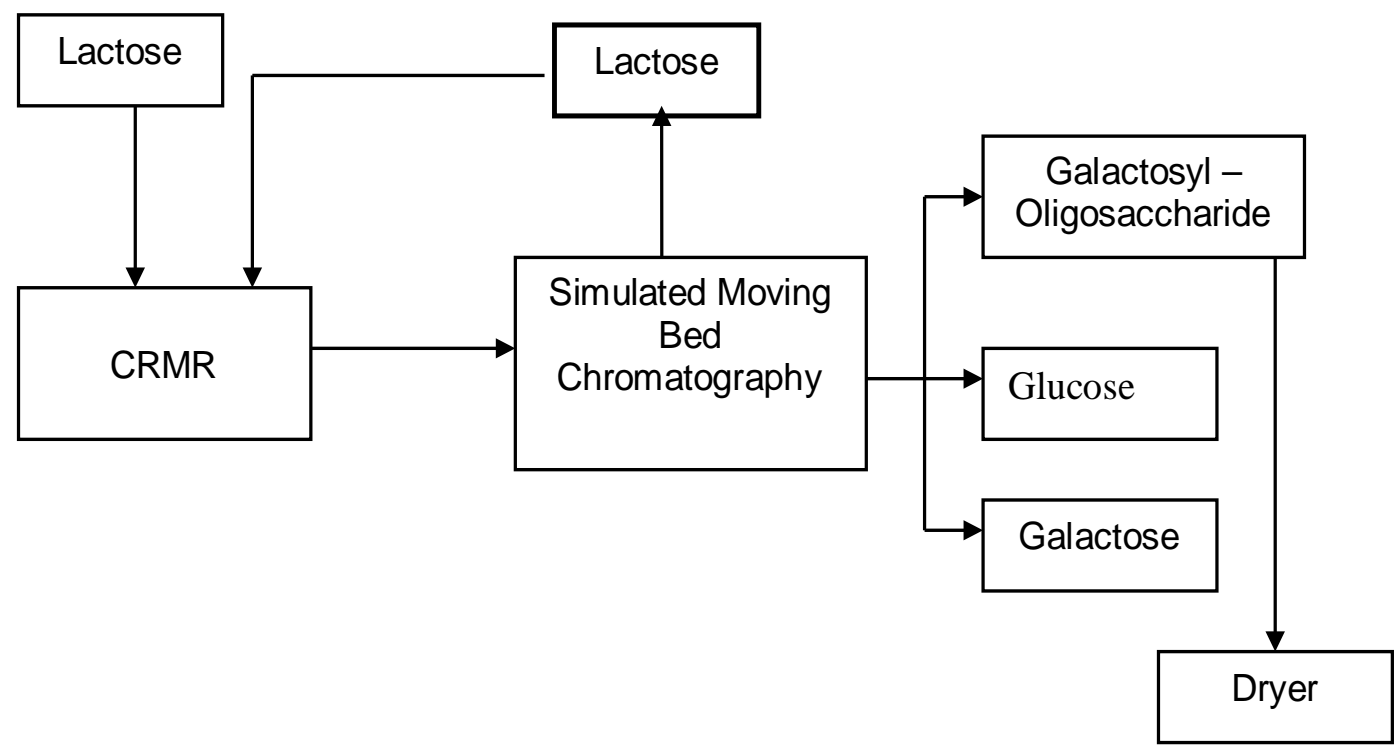

Fig. (9). GOS separation with Simulating Moving Bed Chromatography [21] 
Table 4. Simulated Results PFBR, CRMR in Series and CRMR with Recycle Using Enzyme from A. oryzae

\begin{tabular}{|l|l|l|l|l|}
\hline Reactor Type & $\begin{array}{l}\text { Initial Lactose Concentration } \\
(\mathbf{g} / \mathbf{L})\end{array}$ & Residence Time (h) & $\begin{array}{l}\text { Maximal GOS Concentration } \\
\text { Weight }(\%)\end{array}$ & Volumetric Productivity (g/L.h) \\
\hline \hline PFBR & 200 & 0,5 & 23,6 & 193 \\
\hline PFBR & 400 & 0,5 & 32 & 492 \\
\hline PFBR & 400 & 1 & 34,4 & 90 \\
\hline 2 CRMR & 300 & 0,5 & 34,8 & 192 \\
\hline 2 CRMR & 300 & 1 & 34,7 & 87 \\
\hline 2 CRMR & 300 & 2 & 27,9 & 30 \\
\hline CRMR Recycle & 200 & 0,5 & 39,4 & 184 \\
\hline CRMR Recycle & 300 & 0,5 & 41,7 & 245 \\
\hline CRMR Recycle & 300 & 1 & 38,6 & 99 \\
\hline
\end{tabular}

Based on these considerations, Stella ${ }^{\circledR}$ and Madonna ${ }^{\circledR}$ models were developed for two CRMR in series (Fig. 3), a PFBR, and a CRMR with GOS and Glucose and Galactose production and lactose recirculation (Fig. 9) [21]. The final simulated results obtained are shown in Table 4.

\subsection{Experimental Study}

An experimental study of the same system configurations analyzed in modeling study was developed. Experimental GOS yield and productivity (Table 5) were in good agreement with simulated results (Tables $\mathbf{2 - 4}$ ) and prove the feasibility of these configurations.

\section{DISCUSSION}

Based on the simplified three kinetic constants model implemented a modeling study of CRMR enzymatic GOS production was realized and optimal operation conditions in order to obtain higher GOS yield were defined.

Using the optimal operation conditions defined, simulated running of two CRMR reactors in series and one single PFBR were realized. The PFBR model utilized was a very simplified one, considering ideal operation without carrier limitation.

Finally, an experimental study was realized based on optimal operation conditions defined by the modeling. Results obtained were in good agreement with simulated results for CRMR runs but not for PFBR. Simulated PFBR GOS production results were higher than results obtained experimentally.

Inaccuracies for PFBR simulated results are explained by the very simple conception of PFBR model utilized. To ob-

Table 5. Experimental GOS Yield and Productivity by Various System Configurations

\begin{tabular}{|c|c|c|c|c|c|c|c|}
\hline $\begin{array}{c}\text { Enzyme } \\
\text { From }\end{array}$ & Reactor & Lactose & Max. GOS & GOS Prod. & Lactose & $\begin{array}{c}\text { Residence Time } \\
{[\text { h] }}\end{array}$ & References \\
\hline A. oryzae & PFBR & 200 & 21,7 & 80 & 50 & 0,5 & Albayrak, 2002 \\
\hline A. oryzae & PFBR & 400 & 26,6 & 106 & 50 & 1 & Albayrak, 2002 \\
\hline A. oryzae & CRMR & 260 & 28,2 & 74 & 56 & 1 & Czermak, 2004 \\
\hline A. oryzae & CRMR & 200 & 25 & 50 & 52 & 1 & This study \\
\hline A. oryzae & CRMR & 300 & 34,42 & 201 & 64 & 0,5 & This study \\
\hline A. oryzae & CRMR & 300 & 24,5 & 73 & 46 & 1 & This study \\
\hline A. oryzae & 2 CRMR in series & 300 & 31,1 & 47 & 60 & 2 & This study \\
\hline K. lactis & 2 CRMR in series & 200 & 29,4 & 59 & 81 & 1 & This study \\
\hline K. lactis & CRMR & 300 & 31,7 & 95 & 67 & 1 & This study \\
\hline K. lactis & CRMR & 300 & 32 & 190 & 69 & 0,5 & This study \\
\hline
\end{tabular}


tain better results, a more elaborated model with carrier limitation consideration must be developed.

However experimental results obtained with CRMR in this study were higher than experimental results from PFBR showed previously in literature. The higher PFBR GOS productivity was reported by Albayrak, $106 \mathrm{~g}^{1 \mathrm{~h}^{-1}}$, with initial lactose concentration of $400 \mathrm{~g} \mathrm{l}^{-1}$ [10]. In this study, with

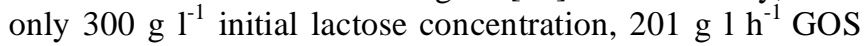
productivity was obtained, representing $89 \%$ increase of GOS productivity.

Moreover, results obtained from two CRMR in series showed higher amount of GOS (about $25 \%$ ) than a single CRMR with average residence time $0.5 \mathrm{~h}$, proving the feasibility of using this approach in order to increase GOS productivity.

Additionally, in this study the advantages of introducing continuous recycling of lactose, using SMBC for separate lactose from final product, were analyzed. With this configuration $100 \%$ conversion of lactose is obtained and initial lactose concentration is also increased. The late is especially important considering the higher the initial lactose concentration is, the higher GOS the yield and productivity are.

The modeling results obtained (Table 4) showed higher amounts of GOS (about $45 \%$ ) than in a single CRMR with the same operating conditions, average residence time $0.5 \mathrm{~h}$ and $300 \mathrm{~g} \mathrm{l}^{-1}$ initial lactose concentration (Table 3), probing the feasibility of this approach.

\section{CONCLUSIONS}

The simplified mathematical model implemented was useful to define the optimal CRMR operation conditions in order to obtain higher GOS yield, but the simplified model implemented for PFBR reactors showed higher GOS production results than experimentally obtained, probing the existence of carrier limitations.

Simulation results showed that running CRMR with an initial batch time between 10 and 30 minutes must be obtained the best GOS production results. Simulation results also confirm that the initial lactose concentration is by far the most significant factor affecting GOS formation with higher GOS yields and volumetric productivities the higher the initial lactose concentration is.

Final GOS concentration increases with residence time up to a maximum concentration obtained below 1 hour residence time and later GOS concentration reduces continuously with increased residence time. GOS productivity increase with residence time only for very low residence time (below 0.1 hour) and after this inflection point, the higher the residence time, the lower the productivity. Better CRMR operation conditions are obtained with as higher initial lactose concentration as possible (30\% weight or higher) and lower residence time ( 0.5 hour or lower).

Experimental CRMR results obtained in this study show $89 \%$ higher GOS productivity than PFBR results showed previously in literature. Simulated and experimental results with two coupled CRMR in series, produced about $25 \%$ more GOS than a single CRMR with average residence time of one hour.
The modeling results obtained for single CRMR combined with SMBC for continuous recycling of lactose, showed about $45 \%$ more amount of GOS than a single CRMR with same operating conditions but without lactose recycling. This shows the feasibility of this process configuration.

The experimental and modeling results obtained in this study show the advantages of using single CRMR or coupled CRMR in series, with or without $100 \%$ lactose recycling, in order to obtain higher GOS productivity with native enzyme production from lactose.

\section{ACKNOWLEDGEMENTS}

The authors are grateful for financial support by the State Ministry of Science and Art of Hessen, Germany and the German Academic Exchange Service (DAAD).

\section{NOMENCLATURE}

$$
\begin{aligned}
& \text { Symbols } \\
& E \quad=\text { enzyme concentration }\left(\mathrm{mol} \mathrm{m}^{-3}\right) \\
& \text { Feed }=\text { feed flow }\left(\mathrm{m}^{3} \mathrm{~h}^{-1}\right) \\
& F_{p 1}=\text { permeate flow to permeate vessel }\left(\mathrm{m}^{3} \mathrm{~h}^{-1}\right) \\
& F_{p 2}=\text { permeate flow from permeate vessel }\left(\mathrm{m}^{3} \mathrm{~h}^{-1}\right) \\
& \text { Frc }=\text { reactor flow }\left(\mathrm{m}^{3} \mathrm{~h}^{-1}\right) \\
& \text { Frp }=\text { retentate flow }\left(\mathrm{m}^{3} \mathrm{~h}^{-1}\right) \\
& G a=\text { galactose concentration }\left(\mathrm{mol} \mathrm{m}^{-3}\right) \\
& G a E=\text { enzyme galactose complex }\left(\mathrm{mol} \mathrm{m}{ }^{-3}\right) \\
& G l=\text { glucose concentration }\left(\mathrm{mol} \mathrm{m}^{-3}\right) \\
& \left.k_{l}=\text { Reaction rate constant } \mathrm{La}+\mathrm{Ga} \rightarrow \mathrm{Ol}\right)\left(\mathrm{s}^{-1}\right) \\
& k_{2}=\text { Reaction rate constant }(\mathrm{Ol} \rightarrow \mathrm{La}+\mathrm{Ga})\left(\mathrm{s}^{-1}\right) \\
& k_{i}=\text { Reaction rate constant }(\mathrm{La} \rightarrow \mathrm{Ga}+\mathrm{Gl})\left(\mathrm{s}^{-1}\right) \\
& \mathrm{La}=\text { lactose concentration }\left(\text { moles } \mathrm{m}^{-3}\right) \\
& L a E=\text { enzyme lactose complex }\left(\mathrm{mol} \mathrm{m}^{-3}\right) \\
& L a E=\text { enzyme lactose complex }\left(\mathrm{mol} \mathrm{m}^{-3}\right) \\
& \operatorname{Tr}=\text { trisaccharides concentration }\left(\mathrm{mol} \mathrm{m}^{-3}\right) \\
& \mathrm{Vp} \quad=\text { permeate volume (1) } \\
& V r c \quad=\text { reactor volume }(1) \\
& \mathrm{Ol}=\text { oligosaccharides concentration }\left(\mathrm{mol} \mathrm{m}^{-3}\right)
\end{aligned}
$$

\section{Indices}

$\begin{array}{ll}0 & =\text { initial } \\ \mathrm{p} & =\text { permeate } \\ \mathrm{rc} & =\text { reactor } \\ \mathrm{rp} & =\text { retentate }\end{array}$

\section{ABBREVIATIONS}

$\begin{array}{ll}\text { GOS } & =\text { galactosyl oligosaccharides } \\ \text { CSTR } & =\text { continuous stirred tank reactor } \\ \text { PFR } & =\text { plug flow reactor } \\ \text { PFBR } & =\text { plug flow bed reactor }\end{array}$



CRMR $=$ continuous recycle membrane reactor
SMBC = simulated moving bed chromatography
HPTLC = High performance thin layer chromatog- raphy

HPAEC-PAD $=$ High Performance Anion Exchange Chromatography, Pulsed Amperometric Detection

\section{REFERENCES}

[1] Czermak P, Ebrahimi M, Grau K, Netz S, Sawatzi G, Pfromm PH. Membrane-assisted enzymatic production of galactosyloligosaccharides from lactose in a continuous process. J Membr Sci 2004; 232: 85-91

[2] Barreteau1 H, Delattre C, Michaud P. Production of oligosaccharides as promising new food additive generation. Food Technol Biotechnol 2006; 44: 323-33.

[3] Mussatto SI, Mancilha IM. Non-digestible oligosaccharides: A review. Carbohydr Polym 2007; 68: 587-97.

[4] Mahoney RR. Galactosyl-oligosaccharide formation during lactose hydrolysis: A review. Food Chem 1998; 63: 147-54.

[5] Dunn JI, Heinzle E, Ingham J, Prenosil JE. Biological Reaction Engineering, Applications and Modelling with PC Simulation, $2^{\text {nd }}$ ed. Weinheim: Wiley VCH 2003.

[6] Boon MA, van't Riet K, Janssen AEM. Enzymatic synthesis of oligosaccharides: Product removal during a kinetically controlled reaction. Biotechnol Bioeng 2000; 70: 411-20.

[7] Petzelbauer I, Splechtna B, Nidetzky B. Developement of an ultra high temperature process for the enzymatic hydrolysis of lactose III. Biotechnol Bioeng 2002; 77: 394-404.

[8] Engel L, Ebrahimi M, Czermak P. Membrane-chromatographyreactor-system for the continuous synthesis of galactosyl-oligosaccharides. Desalination 2008; 224: 46-51.

[9] Engel L, Schneider P, Ebrahimi M, Czermak P. Immobilization of B-galactosidase in adsorptive membranes for the continuous pro- duction of galacto-oligosaccharides from lactose. Open Food Sci J 2007; 1: 17-22.

[10] Albayrak N, Yang ST. Production of galacto-oligosaccharides from lactose by Asperigillus oryzae $\mathrm{B}$-galactosidase immobilized on cotton cloth. Biotechnol Bioeng 2002; 77: 8-19.

[11] Gekas V, Lopez-Leiva MA. Hydrolysis of lactose: A literature review. Process Biochem 1985; 20: 2-12.

[12] Richmond B. An Introduction of Systems Thinking. Hanover: High Performance System Inc 2001.

[13] Macey R, Oster G, Zahnley T. Berkeley Madonna's User Guide Version 8.0. [monograph on the internet]. Berkeley: University of Berkeley; 2000 [Cited 2005 Nov 7]. Available from: http://www.berkeleymadonna.com/

[14] Wallenfels D, Malhotra OP. Galactosides. Adv Carbohydr Chem 1961; 16: 239-98.

[15] Zhou QZ, Chen XD, Li XDC. Kinetics of lactose hydrolysis by Bgalactosidase of Kluveromyces lactis immobilized on cotton fabric. Biotechnol Bioeng 2003; 81: 127-33.

[16] Zhou QZ, Chen XD. Effects of temperature and $\mathrm{pH}$ on the catalytic activity of the immobilized $\beta$-galactosidase from Kluyveromyces lactis. Biochem Eng J 2001; 9: 33-40.

[17] Prenosil JE, Stuker E, Bourne JR. Formation of oligosaccharides during an enzymatic lactose hydrolysis process, (Pt 1 and 2). Biotechnol Bioeng 1987; 30: 1019-25.

[18] Kim CS, Ji ES, Oh DK. A new kinetic model of recombinant Bgalactosidase from Kluveromyces lactis for both hydrolysis and trasngalactosylation reactions. Biochem Biophys Res Commun 2004; $316: 738$.

[19] Ebrahimi M, Gonzalez R, Czermak P. Experimental and theoretical study of galactosyl-oligosaccharides formation in CRMR by thermostable mesophilic enzymes. Desalination 2006; 200: 686-8.

[20] Boon MA, Janssen AEM, van der Padt A. Modelling and parameter estimation of the enzymatic synthesis of oligosaccharides by $\beta$ galactosidase from Bacillus circulans. Biotechnol Bioeng 1999; 64: 558-67.

[21] Czermak P, Nehring D, Ebrahimi M. WO/2005/056810 (2005).

(C) Gonzalez et al.; Licensee Bentham Open.

This is an open access article licensed under the terms of the Creative Commons Attribution Non-Commercial License (http://creativecommons.org/licenses/by-nc/3.0/) which permits unrestricted, non-commercial use, distribution and reproduction in any medium, provided the work is properly cited. 